Available online: https://ejurnalunsam.id/index.php/jagris

\title{
Pengaruh Faktor Psikologik, Sosial dan Finansial Terhadap Kepuasan Kerja Karyawan Penyadap Karet di PT. Atjeh Raya Corpindo Kab. Aceh Timur
}

\author{
Andi Akmal 1 ${ }^{*}$, Siti Balqies Indra ${ }^{2}$, Cut Gustiana ${ }^{3 *}$ \\ 1,2,3 Prodi Agribisnis Fakultas Pertanian Universitas Samudra, Indonesia. \\ *Corresponding author's e-mail: cutgustiana@unsam.ac.id
}

\begin{abstract}
ABSTRAK
Tujuan penelitian untuk mengetahui pengaruh faktor psikologik, sosial dan finansial terhadap kepuasan kerja karyawan penyadap karet (Hevea brasiliensis) di PT. Atjeh Raya Corpindo (ARCO) Kabupaten Aceh Timur. Metode penelitian yang digunakan dalam penelitian ini adalah metode studi kasus.Penentuan lokasi penelitian ini dilakukan secara sengaja (purposive) yaitu di PT. ARCO Kebun Alur Buluh Kecamatan Birem Bayeun Kabupaten Aceh Timur. Objek penelitian ini hanya dibatasi pada karyawan penyadap karet yang ada di PT. ARCOKabupaten Aceh Timur. Jumlah sampel penelitian adalah 33 orang karyawan penyadap dengan menggunakan analisis regresi linear berganda. Hasil penelitian diperoleh faktor psikologik dan faktor sosial berpengaruh sangat nyata. Sedangkan faktor finansial berpengaruh nyata terhadap kepuasan kerja karyawan penyadap tanaman karet di PT. ARCO. Kabupaten Aceh Timur.
\end{abstract}

Kata Kunci:

Finansial; Kepuasan Kerja; Penyadap Karet; Psikologik; Sosial

\begin{abstract}
The aim of this research was to know the effect of psychological, social and financial factors to rubber tappers employees statisfaction in PT. Atjeh Raya Corpindo (ARCO) East Aceh district. This research used case study method. Location was determined purposively in PT. ARCO Kebun Alur Buluh, Birem Bayeun sub-district, East Aceh district. The objects of this research only a rubber tappers with mount of sample 33 person with multiple regression linear. The result showed that psychological dan social factor very effected meanwhile financial factor affected to rubber tappers employees statisfaction in PT. Atjeh Raya Corpindo (ARCO) East Aceh district .
\end{abstract}

Kata Kunci:

financial; employee satisfaction; rubber tappers; psychological, social

How to Cite: Akmal, A., Siti Balqies, I., Cut, G. (2019). Pengaruh Faktor Psikologik, Sosial dan Finansial Terhadap Kepuasan Kerja Karyawan Penyadap Karet di PT. Atjeh Raya Corpindo Kab. Aceh Timur. Jurnal Penelitian Agrisamudra. 6(1): 22-29 


\section{Pendahuluan}

Di era globalisasi ini, dunia bisnis dituntut untuk mampu meningkatkan efisiensi dalam operasinya. Salah satu antisipasinya adalah pengembangan sumber daya manusia yang lebih terampil dan berkualitas. Setiap perusahaan dalam beroperasi mempunyai sumber daya diantaranya adalah sumber daya manusia dan non sumber daya manusia. Sumberdaya manusia mempunyai peran besar bagi kesuksesan suatu organisasi, karena unsur manusia dalam suatu organisasi dapat memberikan keunggulan bersaing dengan membuat sasaran, strategi, inovasi, dan mencapai tujuan organisasi. Sumberdaya manusia merupakan salah satu unsur yang paling penting dalam organisasi, maka salah satu persiapan mengahadapi perubahan-perubahan di masa yang akan datang yaitu dengan mempersiapkan sumberdaya manusia yang berkualitas.

Menurut (As'ad, 2004:112) kepuasan karyawan dapat ditingkatkan melalui perhatian dan hubungan yang baik dari pimpinan kepada bawahan, sehingga karyawan akan merasa bahwa dirinya merupakan bagian yang penting dari organisasi kerja (sense of belonging). Menurut (Rivai, 2009:475) merupakan evaluasi yang menggambarkan seseorang atas perasaan sikapnya senang atau tidak senang, puas atau tidak puas dalam bekerja. Kebutuhan manusia diartikan sebagai segala sesuatu yang dimilikinya, dicapai, dan dinikmati, oleh karena itu manusia terdorong untuk melakukan aktivitas yang disebut dengan kerja, meskipun tidak semua aktivitas dikatakan kerja. Dengan demikian, orang akan merasa puas bila tidak ada perbedaan antara yang diinginkan dengan persepsinya atas kenyataan, karena batas minimum yang diinginkan telah terpenuhi.

Karyawan akan mendapatkan kepuasan akan pekerjaannya bila mereka merasa kesempatan untuk dipromosikan terbuka lebar. Dengan sistem pelaksanaan promosi jabatan yang adil dan merata maka karyawan akan mempunyai anggapan bahwa mereka juga memiliki kesempatan untuk dipromosikan. Setiap karyawan mengharapkan adanya promosi jabatan karena promosi dapat berarti adanya kepercayaan dan pengakuan mengenai kemampuan dan kecakapan karyawan dalam bekerja untuk menduduki jabatan yang lebih tinggi. Promosi jabatan juga diartikan sebagai penghargaan atas keberhasilan karyawan menunjukkan prestasi kerja yang tinggi pada pelaksana tugas-tugas yang dilimpahkan oleh perusahaan kepadanya.

Faktor psikologik meliputi sistem dan perencanaan promosi jabatan pada suatu organisasi. Hal ini akan membuat karyawan menjadi lebih giat bekerja, bersemangat dan berdisiplin, sehingga menciptakan suatu kepuasan kerja bagi masing-masing karyawan dan tujuan perusahaan dapat tercapai secara optimal. Perusahaan juga harus memberikan apresiasi dan penghargaan yang seimbang dan adil kepada karyawan. Salah satu bentuk apresiasi yang diberikan kepada karyawan adalah dengan pemberian kompensasi yang adil kepada karyawan. Karyawan akan merasakan keadilan dalam kompensasinya berdasarkan persepsi mereka akan balas jasa yang diterimanya dari perusahaan.

Faktor sosial adalah bagaimana perusahaan dituntut untuk memberikan dan menciptakan lingkungan kerja yang nyaman dan mencukupi bagi para karyawannya, 
agar karyawan merasa nyaman dengan pekerjaanya. Semakin nyaman dan kondusif lingkungan kerja karyawan maka diharapkan akan mampu meningkatkan kinerja dan semangat kerja karyawan yang pada akhirnya akan memberikan kepuasan kepada karyawan itu sendiri dan kinerja perusahaan. Faktor finansial yaitu kompensasi akan membantu perusahaan untuk mencapai tujuan serta menjaga karyawan dengan baik, sebaliknya, tanpa kompensasi yang cukup, karyawan akan sangat mungkin untuk meninggalkan perusahaan dan untuk melakukan penempatan kembali tidaklah mudah. Akibat dari ketidakpuasan dalam kompensasi yang dirasa kurang adil akan mengurangi kinerja, meningkatkan keluhan-keluhan, penyebab mogok kerja, dan meningkatnya derajat ketidakhadiran dan keluar masuknya karyawan. Sebaliknya, jika terjadi kelebihan dalam kompensasi juga akan menyebabkan perusahaan dan individual berkurang daya kompetisinya dan menimbulkan kegelisahan, perasaan bersalah, dan suasana yang tidak nyaman di kalangan karyawan.

Berdasarkan uraian tersebut, penulis merasa perlu melakukan penelitian untuk mengkaji lebih lanjut fenomena yang ada. Adapun penelitian yang akan dilakukan penulis adalah "Pengaruh faktor psiologik, sosial dan finansial Terhadap Kepuasan Kerja Karyawan Penyadap Karet (Hevea brasiliensiS) DI PT. Atjeh Raya Corpindo (ARCO) Kabupaten Aceh Timur.

\section{Metode Penelitian}

Metode penelitian yang digunakan dalam penelitian ini adalah metode studi kasus. Penentuan lokasi penelitian ini dilakukan secara sengaja (purposive) yaitu di PT. ARCO Kebun Alur Buluh Kecamatan Birem Bayeun Kabupaten Aceh Timur. Objek penelitian ini hanya dibatasi pada karyawan penyadap karet yang ada di PT. ARCO Kabupaten Aceh Timur. Karyawan penyadap tanaman karet yang dimiliki oleh di PT. ARCO Kebun Alur Buluh Kecamatan Birem Bayeun Kabupaten Aceh Timur adalah sebanyak 95 orang (Populasi) yang terbagi dalam 2 Afdeling.

Dari masing-masing afdeling diambil $35 \%$ sebagai sampel secara acak sederhana (simple random sampling). Besaran sampel sebanyak 35\% dari populasi dianggap layak untuk penelitian dengan populasi besar (Prasetyo dan Jannah, 2005:127). Jumlah karyawan (populasi) dan sampel dapat dilihat pada tabel dibawah ini.

\begin{tabular}{lccc}
\hline No & Afdeling Sampel & $\begin{array}{c}\text { Jumlah Populasi } \\
\text { (Orang) }\end{array}$ & $\begin{array}{c}\text { Jumlah Sampel } \\
\text { (Orang) }\end{array}$ \\
\hline 1 & Afdeling I & 64 & 22 \\
2 & Afdeling II & 31 & 11 \\
\hline & Jumlah & 95 & 33 \\
\hline
\end{tabular}

analisis yang digunakan dalam penelitian ini adalah analisis regresi linear berganda, dengan satu variabel dependen $(Y)$ dan tiga variabel independen yaitu variabel $(X)$ dengan persamaan regresinya sebagai berikut :

$Y=a_{0}+a_{1} X_{1}+a_{2} X_{2}+a_{3} X_{3}+e$ 
Keterangan :

$\mathrm{Y} \quad=$ Kepuasan kerja karyawan penyadap karet (skor)

ao $\quad=$ intercept

$\mathrm{X}_{1} \quad=$ Faktor Psikologik (Skor)

$\mathrm{X}_{2} \quad=$ Faktor Sosial (Skor)

$\mathrm{X}_{3} \quad=$ Faktor Finansial (Skor)

e $\quad=$ Error (galat)

Untuk menghitung skor dari variabel bebas menggunakan skala likert. Skala Likert digunakan untuk mengukur sikap, pendapat, dan persepsi seseorang atau sekelompok orang tentang fenomena sosial. Sehingga untuk mengetahui pengukuran jawaban responden pada penelitian ini yang mana menggunakan instrument penelitian berupa kuisioner, penulis menggunakan metode Skala Likert. Dalam pengukuran jawaban responden, untuk gaji, fasilitas dan insentif terhadap kinerja karyawan diukur dengan menggunakan Skala Likert, dengan tingkatan sebagai berikut :

- Jawaban Sangat Setuju (SS) diberi skor $=5$

- Jawaban Setuju (S) diberi skor $=4$

- Jawaban Netral $(\mathrm{N})$ diberi skor $=3$

- Jawaban Tidak Setuju (TS) diberi skor $=2$

- Jawaban Sangat Tidak Setuju (STS) diberi skor $=1$

\section{Hasil dan Pembahasan}

\subsection{Penilaian Karyawan Penyadap Sampel terhadap Variabel Penelitian Faktor} Psikologik (X1)

Faktor psikologik karyawan adalah keadaan yang berkaitan dengan perasaan dan suasana hati karyawan terhadap segala sesuatu yang berhubungan dengan pekerjaan mereka. Faktor psikologik dapat digambarkan dengan indikator pernyataan yang diukur dengan skor yaitu: minat seseorang terhadap bidang pekerjaan, ketentraman yang dirasakan seseorang dalam pekerjaannya, sikap yang ditunjukkan seseorang dalam melakukan pekerjaannya, bakat yang dimiliki seseorang yang berhubungan dengan pekerjaannya dan ketrampilan yang dimiliki seseorang guna mendukung pekerjaannya. Hasil rekapitulasi jawaban karyawan penyadap sampel atas pernyataan faktor psikologik dapat dilihat pada tabel berikut.

Tabel 2. Penilaian Karyawan Terhadap Faktor Psikologik

\begin{tabular}{lcc}
\hline No & Afdeling Sampel & Rata-rata (Skor) \\
\hline 1 & Afdeling I & 3,89 \\
2 & Afdeling II & 4,14 \\
\hline & Rata-rata & 3,97 \\
\hline
\end{tabular}

Sumber: data primer

Dari tabel 2 di atas dapat dijelaskan bahwa rata-rata skor jawaban karyawan penyadap atas pernyataan faktor psikologik adalah sebesar 3,97, dimana artinya 
karyawan memiliki minat, ketentraman, sikap, bakat dan ketrampilan yang baik dari segi psikologik selama bekerja di PT. ARCO Kabupaten Aceh Timur

\subsection{Penilaian Karyawan Penyadap Sampel terhadap Variabel Penelitian Faktor Sosial} (X2)

Faktor sosial karyawan adalah interaksi sosial yang dilakukan karyawan terhadap lingkungan kerja. Faktor sosial dapat digambarkan dengan indikator pernyataan yang diukur dengan skor yaitu: hubungan karyawan dengan sesama karyawan penyadap, hubungan karyawan dengan atasan, hubungan karyawan dengan staf perkantoran, hubungan karyawan dengan masyarakat sekitar perkebunan dan hubungan karyawan dengan anggota keluarga. Hasil rekapitulasi jawaban karyawan penyadap sampel atas pernyataan faktor sosial disajikan pada tabeil berikut.

Tabel 3. Penilaian Karyawan Terhadap Faktor Sosial

\begin{tabular}{lcc}
\hline No & Afdeling Sampel & Rata-rata (Skor) \\
\hline 1 & Afdeling I & 3,88 \\
2 & Afdeling II & 4,06 \\
\hline & Rata-rata & 3,94 \\
\hline
\end{tabular}

Sumber: Data primer

Dari tabel 3 di atas dapat dijelaskan bahwa rata-rata skor jawaban karyawan penyadap atas pernyataan faktor sosial adalah sebesar 3,94, dimana artinya hubungan sosial karyawan terhadap karyawan lain, atasan, masyarakat, staf dan anggota keluarga memiliki hubungan yang baik selama bekerja di PT. ARCO Kabupaten Aceh Timur.

\subsection{Penilaian Karyawan Penyadap Sampel terhadap Variabel Penelitian Faktor} Finansial (X3)

Faktor finansial adalah faktor yang berhubungan dengan gaji dan tunjangan yang diterima karyawan. Faktor finansial dapat digambarkan dengan indikator pernyataan yang diukur dengan skor yaitu: besarnya gaji yang diterima karyawan, besarnya insentif yang diberikan perusahaan kepada karyawan, tunjangan hari raya (THR) yang diberikan perusahaan kepada karyawan, Tunjangan beasiswa yang diberikan perusahaan kepada karyawan dan Tunjangan sewa rumah yang diberikan perusahaan kepada karyawan. Hasil rekapitulasi jawaban karyawan penyadap sampel atas pernyataan faktor finansial disajikan pada tabel berikut.

Tabel 4. Penilaian Karyawan Terhadap Faktor Finansial

\begin{tabular}{lcc}
\hline No & Afdeling Sampel & Rata-rata (Skor) \\
\hline 1 & Afdeling I & 3,75 \\
2 & Afdeling II & 3,90 \\
\hline & Rata-rata & 3,80 \\
\hline
\end{tabular}

Sumber: Data primer 
Dari tabel 4 di atas dapat dijelaskan bahwa rata-rata skor jawaban karyawan penyadap atas pernyataan faktor finansial adalah sebesar 3,80, dimana artinya karyawan merasa puas dengan besarnya gaji, insentif, THR, tunjangan beasiswa dan tunjangan sewa rumah selama bekerja di PT. ARCO Kabupaten Aceh Timur.

3.4. Penilaian Karyawan Penyadap Sampel terhadap Variabel Penelitian Faktor Kepuasan Kerja (Y)

Kepuasan kerja karyawan adalah keadaan emosional karyawan di mana terjadi ataupun tidak terjadi titik temu antara nilai balas jasa kerja karyawan dari perusahaan dengan tingkat nilai balas jasa yang memang diinginkan oleh karyawan yang bersangkutan. yang terdiri atas 5 (lima) indikator pernyataan yang dinilai dengan skor yaitu: kepuasam karyawan terhadap penugasan oleh atasan, kepuasan karyawan terhadap hubungan dengan teman sekerja, kepuasan karyawan terhadap kepemimpinan atasan di perusahaan, kepuasan karyawan terhadap gaji dan tunjangan dan kepuasan karyawan terhadap fasilitas diberikan perusahaan. Hasil rekapitulasi jawaban karyawan penyadap sampel atas pernyataan faktor kepuasan kerja karyawan disajikan pada tabel berikut.

Tabel 5. Penilaian Karyawan Terhadap Faktor Kepuasan Kerja

\begin{tabular}{lcc}
\hline No & Afdeling Sampel & Rata-rata (Skor) \\
\hline 1 & Afdeling I & 4,00 \\
2 & Afdeling II & 4,27 \\
\hline & Rata-rata & 4,09 \\
\hline
\end{tabular}

Sumber: Data primer

Dari tabel 5 di atas dapat dijelaskan bahwa rata-rata skor jawaban karyawan penyadap atas pernyataan faktor kepuasan kerja karyawan adalah sebesar 4,09, dimana artinya kepuasan kerja karyawan merasa puas terhadap penugasan, dengan teman sekerja, terhadap kepemimpinan atasan, terhadap gaji dan tunjangan serta terhadap fasilitas yang diberikan perusahaan selama mereka bekerja di PT. ARCO Kabupaten Aceh Timur.

\subsection{Analisis regresi}

Untuk menganalisis pengaruh faktor psikologik, sosial dan finansial terhadap kepuasan kerja karyawan penyadap tanaman karet di PT. ARCO Kabupaten Aceh Timur digunakan model analisis regresi linier berganda. Hasil analisis linier berganda diperoleh persamaan regresi linier sebagai berikut:

$\mathrm{Y}=0,458+0,324 \mathrm{X}_{1}+0,328 \mathrm{X}_{2}+0,274 \mathrm{X}_{3}$

Dengan interprestasi sebagai berikut:

- Koefisien regresi faktor psikologik (X1) sebesar 0,324. Artinya bila faktor sosial dan faktor finansial dianggap tetap maka setiap kenaikkan faktor psikologik sebesar 1 skor akan diikuti kenaikkan kepuasan kerja karyawan sebesar 0,324 skor.

- Koefisien regresi faktor sosial (X2) sebesar 0,328. Artinya bila faktor psikologik dan faktor finansial dianggap tetap maka setiap kenaikkan faktor sosial sebesar 1 skor akan diikuti kenaikkan kepuasan kerja karyawan sebesar 0,328 skor. 
- Koefisien regresi faktor finansial (X3) sebesar 0,274. Artinya bila faktor psikologik dan faktor sosial dianggap tetap maka setiap kenaikkan faktor finansial sebesar 1 skor akan diikuti kenaikkan kepuasan kerja karyawan sebesar 0,274 skor.

Hasil analisis data secara regresi linier berganda menghasikan nilai R2 (Koefisien Determinasi) sebesar 0,919 artinya bahwa faktor psikologik, sosial dan finansial berpengaruh terhadap kepuasan kerja karyawan penyadap tanaman karet di PT. ARCO Kabupaten Aceh Timur sebesar 91,9\%. Sisanya sebesar 8,1\% dipengaruhi faktor lain yang tidak dimasukan dalam model penelitian ini. Faktor lain dalam hal ini adalah fasilitas kerja, disiplin kerja dan tugas serta wewenang kerja karyawan penyadap tanaman karet di PT. ARCO Kabupaten Aceh Timur. Berikut adalah hasil analisis uji parsial

Tabel 6. Hasil Analisis Parsial

\begin{tabular}{|c|c|c|c|c|c|}
\hline \multirow{2}{*}{ Variabel } & \multirow{2}{*}{$t_{\text {hitung }}$} & \multicolumn{2}{|c|}{$t_{\text {hitung }}$} & \multirow{2}{*}{ Keterangan } & \multirow{2}{*}{ Kesimpulan } \\
\hline & & $5 \%$ & $1 \%$ & & \\
\hline Psikologik & 2,52 & 1,699 & 2,462 & $\begin{array}{l}t_{\text {hitung }}>t_{\text {hitung }} \\
\text { pada } \alpha=5 \% \\
\text { dan } 1 \%\end{array}$ & $\begin{array}{l}\text { Berpengaruh } \\
\text { nyata }\end{array}$ \\
\hline Sosial & 2,523 & 1,699 & 2,462 & $\begin{array}{l}t_{\text {hitung }}>t_{\text {hitung }} \\
\text { pada } \alpha=5 \% \\
\text { dan } 1 \%\end{array}$ & $\begin{array}{l}\text { Berpengaruh } \\
\text { nyata }\end{array}$ \\
\hline Finansial & 2,037 & 1,699 & 2,462 & $\begin{array}{l}t_{\text {hitung }}>t_{\text {hitung }} \\
\text { pada } \alpha=5 \%\end{array}$ & $\begin{array}{l}\text { Berpengaruh } \\
\text { nyata }\end{array}$ \\
\hline
\end{tabular}

Sumber: Data primer

Tabel di atas menunjukkan hasil analisis regresi linier berganda sebagai berikut:

- Nilai t-hitung $X_{1}$ sebesar 2,520 berarti tcari $X_{1}>$ ttabel adalah 1,699 $(\alpha=0,05)$ dan thitung $X_{1}>$ t-tabel adalah 2,462 ( $\left.a=0,01\right)$, sehingga disimpulkan bahwa faktor psikologik secara terpisah berpengaruh sangat nyata terhadap kepuasan kerja karyawan penyadap di PT. ARCO.

- Nilai t-hitung $X_{2}$ sebesar 2,523 berarti tcari $X_{2}>$ ttabel adalah 1,699 $(\alpha=0,05)$ dan $t$ hitung $X_{2}>t$-tabel adalah 2,462 ( $\left.\alpha=0,01\right)$, sehingga disimpulkan bahwa faktor sosial secara terpisah berpengaruh sangat nyata terhadap kepuasan kerja karyawan penyadap di PT. ARCO.

- Nilai t-hitung $X_{3}$ sebesar 2,037, berarti tcari $X_{3}>$ ttabel adalah 1,699 $(\alpha=0,05)$ tetapi t-hitung $X_{3}<$ t-tabel adalah 2,462 ( $\left.\alpha=0,01\right)$, sehingga disimpulkan bahwa faktor finansial secara terpisah berpengaruh nyata terhadap kepuasan kerja karyawan penyadap di PT. ARCO.

\section{Kesimpulan}

Nilai R2 sebesar 0,919 artinya bahwa faktor psikologik, sosial dan finansial berpengaruh terhadap kepuasan kerja karyawan penyadap sebesar 91,9\%. Sisanya sebesar 8,1\% dipengaruhi faktor lain yang tidak dimasukan dalam model penelitian ini. Secara serempak (bersama-sama) variabel faktor psikologik, sosial dan finansial berpengaruh 
sangat nyata terhadap kepuasan kerja karyawan penyadap. Faktor psikologik dan sosial finansial secara terpisah berpengaruh sangat nyata terhadap kepuasan kerja karyawan, sedangkan faktor finansial berpengaruh nyata terhadap kepuasan kerja karyawan penyadap tanaman karet di PT. ARCO Kabupaten Aceh Timur. PT. ARCO Kabupaten Aceh Timur diharapkan dapat meningkatkan kesejahteraan karyawan yang benar-benar menunjukkan kinerja yang baik bagi perusahaan.

\section{Daftar Pustaka}

Anonim, 2015. Laporan Bulanan PT. ARCO. Kebun Alur Buluh Kabupaten Aceh Timur Moh. As'ad, 2004, Phsikologi Industri, edisi keempat, cetakan keenam, Liberty, Yogyakarta

Sudjana, 2005. Teknik Analisa Regresi dan kolerasi, Tarsito, Bandung.

Prasetyo dan Miftahul Jannah. 2005. Metode Penelitian Kuantitatif. PT. Raja Grafindo Persada. Jakarta

Veithzal Rivai, 2009, Manajemen Sumber Daya Manusia Untuk Perusahaan, edisi pertama, cetakan kedua, Raja Garfindo Persada, Jakarta

Veithzal Rivai, 2011, Manajemen Sumber Daya Manusia Untuk Perusahaan, edisi pertama, cetakan kedua, Raja Garfindo Persada, Jakarta 